\title{
A Comparative and Contrastive Account of Research Approaches in the Study of Language
}

\author{
Ahmed Mohammed Saleh Alduais \\ Department of English Language, King Saud University \\ Riyadh, Saudi Arabia \\ E-mail: ibnalduais@yahoo.com
}

Accepted: September 27, 2012 Published: October 20, 2012

Doi:10.5296/ijld.v2i5.2456

URL: http://dx.doi.org/10.5296/ijld.v2i5.2456

\begin{abstract}
A research, in any field, starts with either a passing idea or a bee in one's mind. Research in the field of language study, for instance, in all its branches, is a rich area where in hundreds of ideas and problems can be thought of and investigated. Needless to say, the study of language includes generally (linguistics: phonetic, phonology, morphology, syntax, comparative linguistics, etc.), (applied linguistics: pragmatics, sociolinguistics, psycholinguistics, neurolinguistics, biolinguistics, clinical linguistics, experimental linguistics, computational linguistics, mathematical linguistics, forensic linguistics, corpus linguistics, contrastive analysis, discourse analysis, stylistics and error analysis, etc.), and (educational linguistics: language learning, teaching, and acquisition, etc.). Due to this, a certain problem or an idea in any of the above areas can be investigated from different points of view; that is, using either the correlational research approach, case-study, survey, experimental, ethnographic or the large-scale research approach. Actually, it is claimed in this paper that the above mentioned research approaches are different yet alike. This last point, however, is the major aim of this paper where in the six research approaches are compared and contrasted. At last, the researcher claims that no matter what a researcher in language study will follow since this approach fulfills the questions of his or her study logically, scientifically, and comes up with useful and fruitful bits of information and knowledge.
\end{abstract}

Keywords: Research approaches, Language study, Correlational research, Case-study, Experimental study, Survey study, Ethnographic study, Large-scale study, Comparative and contrastive studies. 


\section{Introduction}

It is a well-known fact that cannot be denied that researches have been greatly influencing everything we do, we want, we plan, we hope we wish and so on and so forth. Naturally, we as people living in this world have and face many problems which either we can sometimes solve directly (consciously) or indirectly (unconsciously). Put it another way, some of the problems which happen in our daily life and as normal people (laymen) we just deal with them in a way that makes us comfortable towards the problems and feel that particular problem has been solved (thinking according to our experience and life events). On the other hand, an educated person (be it a man or a woman) will not feel stratified with interpreting or solving any problem unconsciously; that is, he or she will at least try to philosophise what is going on depending on his or her knowledge on his or her field of study in addition to life experience and day-to-day events (logical thinking).

For instance, let us imagine that two persons, each has bought a kilo of apples. Yet, each one of them has had one apple left with him, the former one is a layman and the latter is an educated man. After two weeks, each one of them has remembered that he still has one more apple left to eat. Unfortunately, when each one of them has come to eat it, he found it (spoilt). Now, the process of research can start from here, the layman, will simply throw it and personally think that the apple is not good to be eaten because it has certain time to be eaten or it will be spoilt. On the contrary, the educated man will at least think in a little more scientific way and will start raising questions such as: what are these things which are appearing on the surface of the apple? What happened exactly to the apple and what will happen exactly if I eat it? Are there facilities which can keep the apple more alive than this time? These questions and other questions for similar or dissimilar problems are exactly the start of conducting, forming what we call here as a (research).

However, if we want to dive into research, researchers will vary in their point of view, each one will discuss the apple problem from different point of views and more importantly in different ways with different tools, but they may all reach the same conclusion(s). What I have just mentioned is called (Research Methodology Approaches). In other words, the researcher (A) may think that she can describe what happened to the apple and conclude her research with certain descriptions to what happened. Another researcher (B), may think that describing what happened to the apple is not enough; that is, he thinks that there must be reasons for what happened and in order to reach them certain proposes (hypotheses) will be proposed and then either investigated or experimented. One more researcher will come and say that I need to collect all kinds of apples and from all countries to see if they are all equal regarding of the period of becoming spoilt. All what I have mentioned above and other ideas and approaches will be introduced comparatively and contrastively in this paper.

Last but not the least, it should be noted that the focus in these approaches is on language study in general rather than general research in all fields. In spite of this, all the approaches which will be mentioned here are not actually different from the approaches used in all fields of study be it social sciences, natural sciences, or medical sciences. For that matter, only examples related to language study will be mentioned in this paper regardless of the general example which has been mentioned above.

To all intents and purposes, the claim that correlational, case-study, survey, experimental, ethnographic and large-scale research approaches are different, yet alike can be introduced comparatively and in contrast under ten headings: possible definition(s) of each approach, 
historical background, nature of each approach, characteristics, uses, role of the researcher, design and format especially data-collection, possible types in each approach, advantages and finally possible and claimed disadvantages for each approach.

\section{The Study}

The six research approaches in the study of language will be introduced both comparatively and in contrast based on the following criteria:

1. Defining each of the six research approaches in the study of language;

2. Historical background;

3. Nature of each of the six research approaches;

4. Characteristics;

5. Uses;

6. Role of the researcher;

7. Design and format;

8. Drawing conclusions;

9. Subtypes of each of the six research approaches;

10. Advantages;

11. Disadvantages.

\subsection{Definitions}

The first area where in the six research approaches can be both compared and contrasted is the possible definition $(s)$ for each approach. Generally speaking, approaches to research have been defined differently from one book to another, but at last these definitions meet in one area which is the core idea of each approach and which nearly all experts in research agree to it.

A correlational research, for example, is defined by (Goodwin, 2010: p. 325) as 'an approach that examines relationships between and among variables'. It is also added that 'a correlation exists whenever two variables are associated or related to each other in some fashion'. He continues 'this idea is implied by the term 'co' for two and 'relation' for, well, relation', (ibid: p. 329).

On the other hand, a case study research is defined as 'a way of investigating an empirical topic by following a set of pre-specified procedures', (Yin, 2003: p. 15). Moreover, (Duff, 2008: p. 21) introduces a case study approach as 'a type of research design and analysis which Gall, Gall and Borg (2003) characterize as the "most widely used approach to qualitative research in education'. More interestingly is Bromley's definition in Duff's as 'the description and analysis of a particular entity (object, person, group, event, state, condition, process or whatever)...', (ibid, p. 22).

Unlike the correlational and case study approaches, a survey study approach is defined by (Walden, 2002: p. xix) as 'a highly developed technique for empirical data gathering'. Additionally, (Grooves, Fowler, Couper, Lepkowski, Singer \& Tourangeau, 2004: p. 2) introduced a survey research as 'a systematic method for gathering information from (a sample of) entities for the purposes of constructing quantitative descriptors of the attributes of the larger population of which the entities are members'.

Dissimilar to the above mentioned approaches is the experimental research approach which is defined simply as 'to experiment is to try', (Srinagesh, 2006: p. 7). In addition, (Johnson, 1992: pp. 164-5) introduces an experimental research as a research approach where in 'a researcher's 
goal is to establish a cause-and-effect relationship between two phenomena'. She goes on 'the researcher aims to establish that one variable, the independent variable, causes changes in another variable, the dependent variable'.

One more approach to be defended here and compared with the above mentioned approaches is the ethnographic research approach. (Hammersley \& Atkinson, 2007: p. 1) introduced their book with an argument about the main differences and misunderstandings between ethnographic research approach and other approaches like case study and qualitative inquiry. However, they define an ethnographic research as 'one of many approaches that can be found within social research today'. They add that a researcher, namely an ethnographer in this kind of research should be involved in 'participating overtly or covertly, in people's daily lives for an extended period of time, watching what happens, listening to what is said, and/or asking questions through informal and formal interviews, collecting documents and artefacts...', (ibid: p. 3). Additionally, (Emerson, Fretz \& Shaw, 1995: p. 1) maintains that 'ethnographic field research involves the study of groups as they go about their everyday lives'.

Last but not the least is the multi-site research approach which (Johnson, 1992: p. 192) defined as 'multisite, multimethod, large-scale research refers to large studies in which a team of collaborating researchers collects data from a number of sites and employs a variety of both qualitative and quantitative data-collection and analysis strategies'.

To conclude, six research approaches have been defined comparatively and contrastively and it has been shown that in terms of definitions they only share the idea that they are all research approaches; otherwise, each of which has been shown as entirely different from one another.

\subsection{Historical Background}

The second area where in the presented research approaches can be compared and contrasted is the historical background of each approach. In general, everything has its history and history they say [repeats itself]. Research approaches; therefore, have started and appeared as they are exactly today. They way each approach has been started and originated, has its story, but in these few lines, the origin of each approach will be mentioned briefly.

Galton (1822-1911) is considered as the father and originator of the correlational research approach, (Goodwin, 2010: p. 327). The idea of the correlational research; that is, finding out correlations has started by collecting data about intelligence and paying some attempts to measure and at the same time to analyse statistically what he has collected. Actually Galton has published a paper called 'Co-relations and their Measurement', (Fancher 1990 in Goodwin, ibid: p. 328).

As for case study approach, it has actually started earlier than the correlational research approach. (Duff, 2008: pp. 24-26) accounts briefly and historically for the early conducted studies starting from Dietrich Tiedemann in 'physical and psychological changes his infant son displayed over the first months of his life', Freud (in psychology), Piaget (biology and cognition), Broca, Wernicke, Gall, etc to the recent day. (Duff, ibid: p. 24) that 'researchers have systematically analysed the observable behaviours of those around them, whether their children, students, clients, or patients, for generations, and applied linguists are no exception in this regard'. He maintains, 'they [applied linguists] have also undertaken in-depth studies of their own or others' communities and social institutions'. 
Compared with the correlational and case study approaches, the survey research approach has may be started to become famous from the $19^{\text {th }}$ century and over. (Groves, Fowler, Couper, Lepkoski, Singer and Tourangeau, 2004, pp. 3-11) provide and account for the historical developmental of the survey study approach in details. It is actually mentioned that such an approach has started by governments by collecting data for the country development purposes. In other words, for academic purposes, that is in schools and universities, it has started later influenced by such conducted researches by the governments of some countries.

Experimental research approach, mainly its recent design has been originated by psychologists and specialists in agriculture science, (Campbell \& Stanley, 1963). In Language study however, linguists, applied linguists, psycholinguists and neurolinguists, etc. feel it is important to start a new era of studying language problems and issues; that is, experimenting such issues and making the study of language scientific-like, (Johnson, 1992).

Unlike the above mentioned approaches, the ethnographic research approach has its origins back to the $19^{\text {th }}$ century, namely to the 'Western anthropology', (Hammersley \& Atkinson, 2007: p. 1). Actually and with reference to (Hammersley \& Atkinson, ibid), anthropologists in the United States and in the Western Europe had started to document: behaviours, cultures, habits and traditions of their cities and towns, from that time onward mainly after 1960, this approach of research has been developed gradually but notably.

Lastly, it seems that every and each of the above mentioned research approaches has its origins, but at last the case study approach seems to be the earliest one to be practiced as compared to other approaches which mostly all share the same beginning; that is, in the $19^{\text {th }}$ century onwards.

\subsection{Nature of each Research Approach}

Nature of each and every research approach is the third area where in they can be compared and contrasted. Basically, when conducting a research, there are at least six approaches. To make it clear, a researcher can design his or her research plan according to one of the following approaches:

1. Correlational research approach

2. Survey study research approach

3. Case-study research approach

4. Experimental research approach

5. Ethnographic research approach

6. large-scale research approach

Strictly speaking, a Correlational research searches for correlations (relationship(s) between one dependent variable and two or more independent variables). The research; however, is simply ended by stating whether the researcher has found relationship(s) between the variables he or she has chosen to investigate or not, (Johnson, 1992 \& Brown and Rodgers, 2002).

A survey study, on the other hand, is interpretive; data-collection is a very important issue in such type of study. The researcher depended on his or her research on what others have said and what others will say about his or her proposed research, (Walden, 2002).

Dissimilarly, a case study is experimental-like and ethnographic-like. In other words, a researcher may be choose or have one case, two or even more to study them in details. 
Furthermore, a researcher role in such type of study is not restricted to description; instead he or she can observe his/her case(s) for either a very short period (say three months) or for a very long period (say a year or more sometimes), (Dyson \&Genishi, 2005).

Unlike this is in the case of experimental research, from the name here, it suggests that an experiment must be done. However, the researcher here can do more than an experiment to either prove or disapprove what he or she has proposed or hypothesized in his or her research. Have done the experiment, a researcher then can decide whether what has been used in such an experiment has an influence or not and this will be the conclusion of his or her experimental research, (Srinagech, 2006).

Different from all the above mentioned approaches is the ethnographic research approach, where in, a researcher has to live the problem and describe it. It should be noted here that may be only approach where in a researcher is not required to pay any efforts for solving any kind of problems as such kind of researches are highly sensitive, (Hammersley, 2007 and Johnson, 1992). It requires the researcher to live in a particular society, community, district, area or even country and then describe in details everything they do (habits, traditions, culture, education in all levels and nearly and simply everything). Needless to say, the results of such researches in this approach can be then compared to current problems in this or that particular society or whatsoever which in turn will help in finding, suggesting or proposing solutions.

Finally the last approach which is actually a mixture of any of the above approaches be it two, three or even all approaches in some cases. On what bases the researcher can decide or choose this approach for his or her research is based on the questions he or she wants to answer or say the hypotheses he or she wants to test and more importantly the results he or she is trying to reach, (Johnson, 1992).

\subsection{Characteristics}

The fourth area for introducing the six research approaches in terms of similarities and dissimilarities is the characteristics of each approach. Generally speaking, researches are at least of three types: 'basic'; that is, theoretical, 'applied' or 'practical', (Seliger \& Shohamy, 1989: p. 19). Yet, researches also have two types in terms of their objectives; either 'heuristic, data-driven, no preconceptions, can generate hypotheses, product is the description of hypotheses', or 'deductive, hypothesis-driven, makes predictions, tests hypotheses and product is a theory', (ibid: p. 31). Again, many writers of books in research methodology differentiate between research approaches in terms of quality and quantity especially in issues relating to data-collection, (look at: Scott \& Morrison 2006, Crano \& Brewer 2002 and Seliger \& Shohamy 1989). Unlike the above mentioned authors, Johnson (1992) had differentiated between research approaches in terms of the way they are conducted. Say it another way, for her, there are six approaches and within these six approaches all the above characteristics can be discussed and mentioned. Thus, the following is a brief description for some characteristics of the six approaches comparatively and contrastively.

To start with the correlational research approach it is usually described as 'relationship studies' and 'prediction studies', (Johnson, 1992: p. 51). (Johnson, ibid: p. 69) adds that correlational research is 'quantitative' and 'essentially reductionist in nature'. Yet, basically such a kind of research 'studies the relationships among characteristics of people or entities, (ibid, p. 49). (Gliner \& Morgan, :p. ix), described the correlational study research approach as the one which searches for 'associations for statistics'. Look at (Bachman, 2004 and Larson-Hall \& Vafee, 
2010) for more details about the use of statistical programmes such as SPSS for doing a correlational research related to language study and assessment.

Unlike the correlational research approach, the case study approach is characterised with 'careful holistic essence', 'usually descriptive' and its description is usually 'contextual', (Johnson, ibid: p. 76). Moreover, it is characterized with its 'bounded system', (Stake 1988 in Johnson: ibid) and 'generally naturalistic', (ibid). Additionally, the case study approach is 'most often primarily qualitative', 'relying on the collection of the naturally occurring data' and 'may be longitudinal', (Johnson, ibid: p. 83). (Seliger, 1989: p. 229) maintains that a case study approach can be both 'qualitative and quantitative', yet it can be both 'synthetic and analytic', (ibid: p. 117) with 'no manipulation' for data and more importantly it is a 'hypothesis-driven', (ibid: p 118). Gomm et al in (Scott \& Morrison, 2006: p. 17) declares that a case study approach is 'ubiquitous', and both Scott and Morrison adds that it is 'interpretive' and 'narrative'.

In comparison with the above mentioned approaches especially with the case study approach, a survey study approach is described as quantitative, primarily descriptive and may involve qualitative interviews, (Johnson, 1992 \& Seliger, 1989). Above all, in a case study research the case or cases are described in details and for that matter it is described as a detailed study. On the other hand, a survey study research cases are 'looked at generally', (Johnson, ibid: 104).

Compared with the correlational research approach, an experimental research approach studies 'effect-cause-relationship', (Johnson, 1992: p. 165) and for that matter, it is usually described as 'comparative', (ibid: p. 168) and contrastive, yet it is 'essentially reductionist', (Johnson, ibid: p. 187) just like the correlational approach. (Seliger, 1989, p. 118) argues that an experimental research must be 'analytic' in nature and it is essentially 'hypothesis-driven' just like the case study approach, but 'manipulation' of data necessarily occurs, unlike the case study data, where in data is and cannot be manipulated.

Once again and for the ethnographic research approach, it is like the case study approach 'descriptive, interpretive, holistic, and naturalistic', but unlike the case study approach, it is 'general' in description [may be similar to the survey study but not identical], with 'anthropological grounding' and 'cultural emphasis', (Johnson, 1992: pp. 133-159), yet it is 'experience-near' rather than 'experience-distance, (Geerz 1984 in Johnson, 1992: p. 159). Thus, (Seliger, 1989: p. 116) maintains that an ethnographic research is 'synthetic' and 'heuristic'.

Lastly, the large-scale research approach which simply can have a number of the above characteristics mixed and brought together according to the used approaches in this or that particular research.

\subsection{Uses}

In addition to the above areas, uses of each approach, is also one area for comparing and contrasting the six research approaches. As a matter of fact, the use of each approach is neither purely optional nor purely obligatorily. Say it another way, a researcher may choose what kind of approach he or she should follow for his or her research, yet in some cases the nature of the research itself and the hypothesized questions are the determiners of the nature (approach) of the research. Thus, the following are some common uses of each approach briefly and with more focus on language study. 
First it should be noted that each and every approach can be used for all fields of study be it humanities including social sciences, pure sciences, natural sciences (applied) or medical sciences in general but with some preferences. For instance, it is common to use the experimental approach for medical and applied sciences in general. On the other hand, fields like sociology, philosophy, language studies in general, (it was common to use) the survey and correlational approaches. Despite this and especially now, all approaches are used in all fields of study and according to the purpose of the study rather than the point that it is medical, humanities and so on and so forth, (for more details about the uses of each approach in all fields look at: (Gerring, 2007), (Brown and Rodgers, 2002), (Campbell and Stanley, 1963), (Walden, 2002), (Hammersley and Atkinson, 2007) and (Johnson, 1992).

Therefore, the use of each approach in language study can be shown through the following detailed example. Suppose that you want to do a research in the field of (neurolinguistics), mainly about Broca's area (an area in the brain responsible for language production). So, in this case, there are not actually a large number of aphasics, a researcher can hardly find some cases. For that matter, in this case a researcher has only two some choices from among the whole approaches. Say it differently, he or she can either study such little cases in details by describing what happened to them and how what happened to them has affected negatively their linguistic ability, or he can and only if the cases are of large number can make a survey study to see to what extent the manifestations of such kind of aphasia are shared among the cases. Instead, a researcher can choose some rehabilitation programmes and do some experiments on the aphasics and if necessary common people to be compared and experimented. However, a correlational or ethnographic study might not be possible for such kind of problems or issues.

In spite of this, all research approaches can be used to search in all language fields be it: theoretical linguistics such as phonetics, phonology, morphology, syntax and semantics, or applied linguistics such as pragmatics, psycholinguistics, neurolinguistics, sociolinguistics, forensic linguistics, computational linguistics, and of course language teaching and learning issues in all its kinds (as a foreign, second or even third language), (for more details about the use of each approach in language study: (Duff, 2008 [for case study approach], Brown and Rodgers 2002 \& Cohen, Manion and Morrison 2000 [for the correlational approach], Johnson 1992 \& Crano and Brewer 2002 [for all other approaches].

\subsection{Role of the Researcher}

The sixth area where in the six research approaches can be compared and contrasted is the role of the researcher. Needless to say that the researcher in each and every kind of research is the major-role-player in conducting the research, yet this degree of role-playing can vary from one approach to another. For that matter, the following is an attempt to show such differences and similarities between what a researcher in each approach does/must do, follow/must follow, etc.

Firstly, it should be noted that the researcher actually is the one who nearly leads the whole process of research whatever kind of research was it. Yet, the main idea here is to discuss the role of the researcher in administrating the research from data-collection and to results and conclusions. Put it simply, there are certain matters in certain approaches which a researcher cannot interfere with and he or she can only follow. On the other hand, other certain approaches allow the researcher to manipulate and control some aspects in the research.

The correlational research, for example, the role of the researcher starts by collecting data and after that the researcher is lead by statistics; that is, computing the collected data and reporting 
it as it has been shown statistically. It is considered as unethical and immoral, yet I would say [illegal] to attempt manipulating the data (numbers) to suit the ideas in your mind.

Similarly, in the case of the survey research approach, the researcher's role ends with data-collection. In other words, ha data been collected, then the researcher [must] only follow the results and report such results to say if they prove or disapprove what he or she has hypothesized. Again, it should be mentioned, a researcher must be warned not to try any attempts of manipulating the data to serve his or her own ideas.

Once again, in the experimental research approach, a researcher when conducting an experiment, he or she should report frankly what has appeared in terms of cause-effect-relationship. Therefore, the difference here is that the researcher has the choice to manipulate the subjects of the experiment to serve his or her own proposed ideas, but not to fake the results of the conducted experiment(s). Actually, in both the correlational and survey research approaches, the researcher should not select his or subjects to serve the ideas he or she wants to investigate or introduce. Instead, he or she observes and tests randomly and select subjects which are representative for as much population as possible so that the data and most importantly results can be valid and reliable.

Similarly, in the case of the case study research approach, the major role of the researcher is to describe as accurately as possible what happened, what is happening and what has happened to the case he or she has selected to his or her research. In this kind of research, however, the researcher may end his or her research by a proposed theory or hypothesis which must be investigated rather than testing a certain hypothesis as in all above mentioned approaches.

Like the case study researcher, an ethnographer (researcher) also describes what is going on culturally, socially, psychologically, linguistically, economically, and so on and so forth. As a matter of fact, in such kind of research and also in the case study research approach the researcher is the instrument of the research. That is to say, unlike the correlational, survey, and experimental approaches the instruments of the research are (data and use of statistics in the case of the correlational and survey approaches and the experiment itself in the case of the experimental research).

Finally, the role of the researcher(s) in the large-scale research approach, and here it should be noted that it is rarely to find a researcher alone carries such kind of research. Say it another way, such kind of research is usually if not always conducted by a team of researchers who share the tasks and roles throughout the whole process of the research.

\subsection{Design and Format}

One more area (the seventh) for introducing the claim that the six research approaches are different yet alike is the design and format of each approach. Actually, the way a researcher designs and formats his or her research can decide the future of his or her research! To some extent, one could say that both design and format of each and every approach of research is similar yet dissimilar.

As a matter of fact, in each research approach, a researcher could not escape to include the following sections in his or her research be it: a correlational, case study, survey, experimental, ethnographic or multi-scale research.

1. Research questions or hypotheses

2. Context of the research 
3. Participants, their selection and relevant characteristics

4. Theoretical orientation of the researcher

5. Role of the researcher

6. Data-collection procedures

7. Data-analysis and findings

8. Drawn conclusions and their relation to the collected data

9. Contribution of the study to the field/knowledge or whatsoever

10. Implications or recommendations

Therefore, the above mentioned headings can be used as criteria for analysing any research approach, namely for standard research samples for each approach. Hence, in this part more concentration will be paid to (data-collection), (data-analysis) and (drawn-conclusions). Though even in the other parts one may find slight differences, but they are to a great extent similar. For that matter, only the above mentioned three points will be introduced in somehow details.

As a matter of fact, both correlational and survey research approaches have much in common especially in terms of data-collection. To make it clear, in both approaches a researcher is to a great extent basing in numerical results and only numbers which decide the results, drawn-conclusions and yet implications of the research. However, the data is collected may be through questionnaires, tests, interviews, but at last everything is evaluated numerically and quantitatively rather than descriptively and qualitatively.

On the other hand, both case study and ethnographic study approaches are to a great extent similar in terms of data-collection. In other words, in both cases, the researcher has to live with his or her cases with a little bit difference in the former the researcher has a little number of cases and he is concerned with one issue and one area, and in the latter, the researcher is living the culture and describing may be everything happening around him or her and more importantly he or she is investigating a larger population.

Like the correlational and survey research approaches is the experimental research approach in terms of numerical results which will decide the significance of the results; that is, in terms of cause-effect-relationship, in case the significance is close, so it means the suggested and alternative solutions have been introduced are not useful. Yet, like the case study and ethnographic study approaches is the experimental research in terms of collecting naturally-occurring-data; it is necessary that the researcher applies his or her experiment(s) on the selected subjects. It should be noted that in the case of both the correlational and survey research approaches, the researcher may not necessarily meet the subjects; he or she can communicate through email or post instead.

In general; however, a researcher can collect his or her data using: (questionnaires, interviews [mostly for correlational and survey researches]), (documenting, tape-recording, video-taping, observing, [mostly for case and ethnographic researches], and conducting experiments, pretesting and posttesing [mostly for the experimental research]).

Above all, it should be noted clearly that the 'primarily qualitative, naturalistic, descriptive', (Johnson, 1992: p. 83) case-study and the ethnographic study approaches are unlike all other approaches in case of plan or proposal preparation. In other words, while in all other approaches nearly everything is planned in the beginning, in both case-study and ethnographic 
study modification and refinement of the plan goes on till nearly the end process of the research.

Having introduced data-collection, then data-analysis in all approaches will be introduced briefly. Again, for the correlational, survey and experimental research approaches numbers are very important to the extent they decide the rest sections of the research. As for the way of analysing the data, it can be simply done with the use of statistics programmes including Excel and SPSS as the most frequently used ones. One could infer from this that the researcher is no more interfering with the research here; he or she is following the numerical results which will be later interpreted to description (language instead on numbers). Nevertheless, it should be noted that data-insertion must be done carefully for any mistakes or misuse of such programmes would result and lead to fake and misleading results, (Bachman, 2004 and Larson-Hall \& Vafee, 2010).

Different from this is in the case of the case-study and ethnographic research approaches where in the data is analyzed inductively and intuitively. Unlike this is in the case of the above three approaches where the data-analysis is deductive, (Hancock \& Algozzine, 2006 and Hammersley, 2007).

\subsection{Drawing Conclusions}

Basically, a correlational research is conducted to find correlations between two or more variables and a survey research approach is conducted to find generalizations about a certain issue or topic. On the other hand, a case study is conducted to investigate a certain issue in details in a certain case or cases and an ethnographic study is conducted usually for documentary and analysis purposes. Last but not the least, an experimental research is conducted to test a certain hypothesis/hypotheses and either prove the usefulness of a certain proposed hypothesis or continuing the use of the earlier one and the failure of the introduced one for either finding equal results (advantages) or very close ones.

With reference to what I have mentioned above, results in the survey and correlational research approaches are more qualified to be generalized for the rule is that the larger the number of the subjects is, the more chance for generalizing the results of the research to other subjects. For that matter, in a case study, it is not logical to generalize what you have reached to. Similarly, in the case of the ethnographic research, because cultures, habits, traditions, behaviours and so on and so forth are not only different from one country to another but within the same country and the same area on can find big differences. In spite of this, it does not mean that if a survey study was conducted in Yemen for example, to be generalized for the people of Saudi Arabia; instead a researcher can make use of the results and tool to make the process of the research easier instead of starting from nil.

Finally, for the experimental results the same thing will be applicable. Suppose that, a research has been conducted in Saudi Arabia, at King Saud University, College of Arts, Department of English Language and Literature. The claim of the research is that the use of computer, namely Word Processor is more effective for teaching writing in a second language setting for the students in the Department of English, than the traditional method of teaching (chalk and pen). However, even if the results would come in favour of this claim significantly, generalizing the results would not be logical for other countries and other settings. Say it another way, suppose this would be suggested for the universities in a country like Yemen, first they cannot provide computer labs for the students to do so. Secondly, the students there think that handwriting and typewriting should go together and this is may be the view of some other researchers who may 
be would agree with me that students need not only to be able to typewrite, but also and more importantly to write with hand (handwriting).

\subsection{Subtypes of each Research Approach}

It has been mentioned earlier in this paper that six research approaches will be compared and contrasted. Nevertheless, in this part certain subtypes within each research approach will be mentioned briefly and this is the ninth area where comparison and contrast among the approaches can be introduced.

In the beginning, let's recall the six approaches of research: correlational, case-study, survey, experimental, ethnographic and large-scale research approach.

Again it should be noted that all the types or say varieties within each research approach are argumentative for some research methodologists would not clearly and sharply differentiate between and among such types.

To start with the correlational research approach, there are actually two types and with each type there are also two types. (Johnson, 1992: p.62) has differentiated and contrasted merely between two types: the former is simple correlational research and the latter is complex correlational research. However, the major difference between such types is that one which is simple is only concerned with correlations or associations between certain variables. On the other hand, the complex correlational research has much in common with the experimental research for it merely accounts for things such as influence, effect and cause, etc. In contrast, (Mackey \& Gass, 2005: p. 145), contrast and compare between two types of the correlational research, namely relational and predictive research. Again, the major difference between such types is that the former is purely correlational and the latter is partially correlational for the researcher attempts to predict and speculate a thing which is rarely done by correlational researchers. Hence, it should be noted that all above types share one thing which is searching for correlations between/among variables which make them all categorized under the correlational research.

The second type of research approach is the case study research approach. Actually, in the case of this approach two types are to be compared and contrasted: one is single-case-study and the second is the multiple-case-study. To make this point clear, let us provide this example, suppose that a researcher is doing a case-study studying, for example, the manifestations of dyslexics from a neurolinguistic perspective, so the type of his or her case study can be decided by the cases he or she will use for the study. Put it another way, in case the researcher has found more than a dyslexic case and it is possible to meet them and arrange meetings with them, so the study will be a multiple-case study, yet an explanatory rather than descriptive. On the contrary, if the cases are not there and only their medical records are available and it has become difficult to reach them, so the study will be descriptive or/and exploratory rather than explanatory. Finally, if there is only one dyslexic case from among all the cases available in the hospital so the study will be considered as a single-case study. Thus and simply, one can infer that a single-case-study means only one case (one subject) and a multiple case-study means more than one case. Again and be it a single or a multiple-case study, if the case(s) is/are met and interviewed then it is to be considered as explanatory. On the other hand, if only their data; that is archival records, then the study is descriptive or/and exploratory rather than explanatory, (Yin, 2003: pp. 41-46) and (Mills, Durepos \& Wiebe, 2010).

The third type is the survey research and within this approach, (Powell 1997 in Walden, 2002: p. 322) differentiated between: cross-sectional survey, trend, cohort, panel, longitudinal, 
parallel samples, contextual, socio-metric and finally critical incident survey. Despite this, there are only two major types which are cross-sectional and longitudinal. Once again, the major difference between these two types has been clarified by (Scott \& Morrison, 2006) in terms of data- collection. Put it differently; whereas the data in the cross-sectional survey is collected at one time only, in the longitudinal survey it is collected gradually and repeated several times to see if there are any changes which have occurred during a certain period of time.

The fourth type of research is the experimental research and within this approach, two types of research have to be distinguished, namely, experimental and quasi-experimental researches. Basically, in the experimental research approach there are three major characteristics: control, manipulation and randomisation. However, in case any of these three characteristics is not achieved the research is considered as quasi-experimental rather than experimental. Nevertheless, the quasi-experimental research like the experimental research has data which can be manipulated. Yet, unlike the experimental research, the quasi-experimental research can either have no control group, no random selection, no random assignment nor active manipulation of variables, (Gliner \& Morgan and Fitzpatrick \& Wallace).

The fifth type of research approaches is the ethnographic research approach where in there are actually no sharp and accurate statements which indicate that there are certain types within such an approach. In spite of this, (Hammersley and Atkinson, 2007) have mentioned that a clear distinction must be made between auto-ethnographic research, virtual-ethnographic and ethnographic research (real ethnographic research). While the auto-ethnographic research is the one which narrates or describes the history if a person or individual-life histories, the virtual ethnographic research is totally based on downloaded data, say from the internet, archival records, etc. Dissimilar to these two types is the real ethnographic research where in a certain society, community, etc. is being observed and described in details. Above all, (Hammersley and Atkinson, 2007) have clarified the argument between ethnographers in terms of three approaches: positivism (they encourage quantitative data and neglect the natural occurrence of the data-collection), naturalism (they emphasize on natural occurrence of date and encourage for qualitative data), and reflexivity (a mixture of both approaches).

\subsection{Advantages}

In addition to the above nine areas, advantages of each approach is also one area to compare and contrast among the six research approaches. Certainly, nothing and none is perfect. In other words, each of the above mentioned research approaches has its own advantages, yet disadvantages. Thus, the following is an attempt for first major [claimed] advantages of each approach and then some major [disadvantages].

To start with the correlational approach it has its strength in its ability to 'alert us with associations among variables', yet a researcher to some extent can draw some reasonable generalizations, (Johnson, 1992: p. 69).

To move to the case study approach, such an approach actually is characterized by the 'holistic look at a case in the context of the bounded system on yielding many rich insights about', (ibid: p. 99), the investigated issue. (Gerring, 2007) adds that a case study has its power on its depth. More importantly, (Duff, 2008: pp. 42-58) discusses a number of the major advantages of such type of research approach which include: 'completeness, depth of analysis, readability, and a researcher may generate new hypotheses, models and understandings about the nature of' the investigated topic or study area. He adds, a well-conducted case study is characterized by its 
'thick description and triangulation, exploratory innovative potential and role in theory building, uniqueness, and finally longitudinal feature', (ibid).

Dissimilar to both correlational and case-study approaches, the survey study research approach has its strength on its 'breadth... for providing a broad view of issues' and 'for capturing the essence of trends', (Johnson, 1992: p. 128). Moreover, the survey study research is advantageous for planning and adding knowledge in or about a particular issue, field related to language study or any other field of study, (Johnson, ibid \& Walden, 2002).

On the other hand, 'carefully specified experiment procedures allow rigorous control and provide relatively unambiguous results for a limited set of questions, (Porter 1988 in Johnson, 1992: p. 187). Furthermore, an experimental research approach is considered as 'powerful' for its ability to 'establish cause-and-effect relationships', (ibid) between certain variables, a thing which cannot be achieved by conducting a correlational research especially of simple type.

From among all the above approaches, the ethnographic research approach has its strength on its ability to offer 'grounded insights not usually available through approaches of the hypothetico-deductive type', (Johnson, 1992: p. 159). Above all, it 'opens new ways for both teachers and students to be more involved in constructing knowledge that will ultimately improve practice', (ibid).

The last approach is the large-scale approach and its major advantages can be explained under its ability for conducting 'cross many site' researches, 'depth and breadth' and most importantly being conducted collaboratively (many researchers or say a team), (Johnson, 1992: p 209).

\subsection{Disadvantages}

The last area (the tenth) where in the claim that the six approaches are similar yet dissimilar is the possible and claimed disadvantages of each approach. Have mentioned some of the major benefits of each approach; however, now a number of the major downsides for each approach will be also mentioned.

From among the negative points of the correlational research approach is that it is 'essentially reductionist in nature', 'traditionally, it has been criticized for its inability to determine cause-effect relationships', (Johnson, 1992: p. 69). Additionally, 'it does not provide us with rich insights about individual language learners', (ibid) in the case of researches related to language studies and [about individual issues and topics] in researches related to other fields of study.

In contrast, the case-study approach has also its weaknesses. Consider for instance, its non-rigorousness, the inability to generalize findings from the hypothetico-deductive perspective, (Johnson, 1992: p. 99). (Duff, 2008: pp. 42-58) discussed the possible drawbacks of the case study approach in terms of certain points which include: inability of generalizability, objectivity versus subjectivity, data-driven rather than theory-driven, and attrition'.

As for the survey research approach, its minus points can be found under its inability to yield conclusions about cause-effect relationships. Moreover and according to (Johnson, ibid: p. 128), 'no survey is value free or theory free' and the uselessness of the survey research 'for illuminating processes in L2 deeply and in details' compared to the case study. Lastly, a survey 
research is not totally representative especially in cases related to society, culture, community involvement if compared to the ethnographic research approach which allows such things, (ibid \& Walden, 2002). Actually (Walden, ibid: p. 47) stressed on one disadvantageous point of the survey research which is that in some case it requires high costs.

Like the correlational research approach, the experimental research approach is being criticized for that it is 'essentially reductionist in nature' plus the original questions of the study in some case 'may have been misguided', (Johnson, 1992: p. 187).

Similar to the survey research approach, the ethnographic research approach is highly criticized for its high costs. More importantly, the researcher is sometime putting himself or herself into hot water, (Hammersley, 2007: p. 96). In other words, living and being involved in a new society, community if not a county is a danger by itself and requires the researcher to be very cautious, yet very careful about every and each action he/she performs, every word he or she says, and so on and so forth.

Finally, the large-scale research approach where in one of the hatches of both survey and ethnographic research approaches can be shared which is high costs of such kind of research especially and with reference to (Johnson, 1992: p. 69), 'if the research questions are somehow misguided, large amount of public funds might be spent for little benefit'.

\section{Conclusion}

All in all, research is knowledge and knowledge is research. In order to increase knowledge in any field of study in general and in language study in particular, we need a system, tools, principles etc. so that our work looks systematic, scientific logical and reasonable. Six research approaches have been introduced in this paper comparatively and in contrast. Actually, it has been claimed by the researcher that such approaches are similar yet dissimilar.

In order to clarify and proof such a claim, however, ten areas have been introduced in described. These areas include: a definition or two for each approach, historical background, nature of each approach, characteristic, uses, role of the researcher, design and format, possible types within each research approach, some major advantages, and finally some major possible and claimed disadvantages for each of the above named research approaches.

Consider, for instance, the correlational, survey and experimental research which have much in common especially in the case of more quantitative data, yet less qualitative data. Similarly, in the case of the case-study and ethnographic research approaches which have much in common such as the researcher is totally involved in the process of research; that is, he or she is a concrete participator rather than a tool as in the other approaches [leading the process of research]. Yet, clear-cut differences between the two approaches are possible and they include: the former investigates individuals, the latter a group, society, community, etc. Once again, the first one stresses on differences between individuals, the second on, on the other hand, stresses on the shared features.

To sum up, it has been shown what could be similar in two or more approaches could be dissimilar in another approach especially in the case of quantitative and qualitative characteristics. Again, what could be a plus point in a certain approach may be a minus point in another research approach. Lastly and as far as I am concerned, more research papers describing similarities and differences in the above research approaches mainly for the study of language can be conducted in more depth and with taking into consideration providing sample 
study plans, or say proposals for each and every approach on condition that the samples carry one idea, but show how it will be conducted properly in every and each research approach. At that time, such a study will be considered as not only comparative and contrastive, but even and more importantly practical and can lead a beginner researcher in the field of language study to the right way of putting the flesh on the bone.

\section{Acknowledgement}

The researcher would like to express his gratitude to Dr. Ibrahim Haji-Hassan (previously associate professor of Applied Linguistics and Sociolinguistics, Department of English Language, King Saud University, Riyadh, Saudi Arabia) for his inspiring ideas about research approaches in the study of language.

\section{References}

Bachman, L. F. (2004). Statistical Analyses for Language Assessment . Cmabridge : cambrdige University Press.

BIBLIOGRAPHY $\backslash 1033$ Scott, D. \& Morrison, M. (2006). KEY IDEAS IN EDUCATIONAL RESEARCH. New York, London : Continuum International Publishing Group.

Brown, J. D. \& Rodgers, Th. S. (2002). Correlational Research: language learning/language attitudes . In J. D. Brown \& Rodgers, Th. S., Doing Second Language Research: Oxford Handbook for Language Teachers (pp. 157-193). Oxford : Oxford University Press, available online

at: http://books.google.com.sa/books?id=PjXiSnZeS6AC\&pg=PA184\&dq=correlational+researc $\mathrm{h} \& \mathrm{lr}=\& \mathrm{ei}=\mathrm{RNz}$ _S_PUCpiWyASauqGkDQ\&cd=16\#v=onepage $\& \mathrm{q}=$ correlational $\% 20$ researc h\&f=false, retrieved at: 27, May 2010.

CAMPBELL, D. T. \& Stanley, C. J. (1963). EXPERIMENTAL AND QUASI-EXPERIMENTAl DESIGNS FOR RESEARCH . Dallas Geneva, III. Hopewell, N.J. Palo Alto London: HOUGHTON MIFFLIN COMPANY BOSTON.

Cohen, L., Manion, L. \& Morrison, K. R. B. (2000). Correlational Research. In L. Cohen, Manion, L. \& Morrison, K. R. B. Research Methods in Education (5 ed., pp. 191-202). Routledge Falmer, available online at: http://books.google.com.sa/books?id=tD81P40zoHoC\&pg=PA191\&lpg=PA191\&dq=correlat ional+research\&source=bl\&ots=FsUeoKaycV\&sig=iZj5zgt10kot9xceVF6MNGGCLvs\&hl= ar\&ei=KNf_S5aeBIWMOO6t-MwO\&sa=X\&oi=book_result\&ct=result\&resnu, retrieved at 27, May 2010.

Crano, W. D. \& Brewer, B. M. (2002). Principles and Methods of Social Research (2 ed.). Mahwah, New Jersey London: LAWRENCE ERLBAUM ASSOCIATES, PUBLISHERS.

Duff, P. A. (2008). Case Study Research in Applied Linguistics. New York, London: Taylor \& Francis Group, LLC.

Dyson, A. H. \& Genishi, C. (2005). On the Case Approaches to Language and Literacy Research (Vol. (AN NCRLL VOLUME)). Columbia University,New York and London: Teachers College Press and National Conference on Research in Language and Literacy.

Emerson, R. M., Fretz, R. I. \& Shaw, L. L. (1995). Writing Ethongraphic Fieldnotes . Chicago and London: The University of Chicago Press. 
Fitzpatrick, J. J. \& Wallace, M. (Ed.). (2006). ENCYCLOPEDIA OF NURSING RESEARCH. New York: Springer Publishing Company, Inc. Availble online at: http://books.google.com.sa/books?id=ojdhsVqdmawC\&printsec=frontcover\&dq=encyclopedi $\mathrm{a}+\mathrm{of}+$ nursing+research\&cd=1\#v=onepage \&q\&f=false, retrieved at: 14, June 2010.

Gerring, J. (2007). Case Study Research: Principles and Practices. Cambridge, New York: Cambridge University Press.

Gliner, J. A. \& Morgan, G. A. (2002). Research methods in applied settings: an integrated approach to design and analysis . Lawrence Erlbaum Assoicates, Inc., Publishers. Available online at: http://books.google.com.sa/books?id=spywIgzp4vwC\&printsec=frontcover\&dq $=$ research $+\mathrm{m}$ ethods+in+applied+settings\&cd=1\#v=onepage \&q\&f=false, retrieved at 14, June 2010.

Goodwin, C. J. (2010). Correlational Research. In C. J. Goodwin, Research in Psychology: Methods and Design (pp. 325-362). John Wiley and Sons, available at: http://books.google.com.sa/books?id=eNsVUGTMcDoC\&pg=PA325\&dq=correlational+rese arch\&ei=xtn_S86pApWWyQSRrumNDA\&cd=6\#v=onepage \&q\&f=false, retrieved at: 27 , May 2010.

Gray, D. E. (2009). Doing research in the real world. London: SAGEPublications Ltd. Available online

at: http://books.google.com.sa/books?id=14dEQTQ11NYC\&printsec=frontcover\&dq=Doing+res earch+real+world\&cd=1\#v=onepage\&q\&f=false, retrieved at: 14, June 2010.

Groves, R. M., Fowler, F. J., Couper, M. P., Lepkowski, J. M., Singer, E. \& Tourangeau, R, (2004). Survey Methodology. A JOHN WILEY \& SONS, INC., PUBLICATION.

Hammersley, M. \& Atkinson, P. (2007). Ethnography: Principles in practice (3 ed.). Taylor \& Francis e-Library.

Hancock, D. R. \& Algozzine, B. (2006). Doing Case Study Research: APractical Guide for Beginning Researchers. Columbia University, New York and London: Teachers College Press.

Johnson, D. M. (1992). Approaches to Second Language Learning . London, Melbourne, Auckland, Toronto: Longman Group Ltd.

Larson-Hall, J. \& Vafaee, K. (2010). A Guide to Doing Statistics in Second Language Research Using SPSS. New York : Taylor \& Francis.

Mackey, A. \& Gass, S. M. (2005). Second Language Research Methods: Methodology and Design. Lawrence Erlbaum Assoicates, Inc., Publishers, Availabe online at: http://books.google.com.sa/books?id=lMxQ2jQ_uCAC\&printsec=frontcover\&dq=second+la nguage+research:+methods+and+design:+Mackey+and+Gass\&cd=1\#v=onepage \&q\&f=false, retrieved at 14, June 2010.

Mills, A. J., Durepos, G. \& Wiebe, E. (Eds.). (2010). Encyclopedia of case study research. SAGE Publications, Inc.

Seliger, H. W. \& Shohamy, E. (1989). Oxford Applied Linguistics: Second Language Research Methods . Oxford: Oxford University Press. 
Srinagesh, K. (2006). The Principles of Experimental Research. Elsevier Inc.

Walden, G. R. (2002). SURVEY RESEARCH METHODOLOGY, 1990-1999:An Annotated Bibliography. Westport, Connecticut . London: GREENWOOD PRESS.

Yin, R. K. (2003). Case Study Research: Design and Methods. Thousand Oaks, London, New Delhi: Sage Publications . 